\title{
Ensuring effluent standards by improving the design of Rotating Biological Contactors
}

\author{
D. Mba, R. Bannister \\ School of Engineering, Cranfield University, Cranfield, U.K \\ d.mba@cranfield.ac.uk
}

\begin{abstract}
The Rotating Biological Contactor (RBC) is used for both municipal and industrial wastewater treatment; however, the $\mathrm{RBC}$ has been plagued with mechanical deficiencies since its conception. The unpredicted loss of mechanical integrity results in loss of operation and the discharge, into the environment, of effluent that does not meet consent standards as set by governmental bodies. The consequence of the latter on aquatic life cannot be understated. Whilst maintaining an effluent standard is of vital importance this has to be balanced against the capital costs of $\mathrm{RBC}$ units. In addition to detailing reasons for defects associated with RBC's this paper presents a novel design approach for shaftless RBC's. This novel design takes cognisance of the mechanisms and reasons for mechanical failure, thereby reducing occurrence of loss operation of RBC units and ensuring that the effluent continually meets discharge standards. The added significance of the design is a $50 \%$ reduction in costs.
\end{abstract}

Key words- Corrosion fatigue, hydrogen embrittlement, microbiologically influenced corrosion, rotating biological contactor. 


\section{Introduction}

The RBC process is used worldwide for both municipal and industrial wastewater treatment. The principle of the RBC was originated in the early part of the century and today there are many thousands of units operating world wide. RBC units can be designed for both organic carbon removal and nitrification. The RBC operates continuously throughout its life, however a break in operation will necessitate attention by the operator to maintain effluent consent standards. Failure to meet consent standards can have disastrous consequences for life in the nearby estuary. Furthermore heavy fines can result from failure to meet the compliance set. For example in March 2002 Anglian water, UK, was fined $£ 200,000$ for polluting the water in Crouch (Essex, UK) [1], the highest fine ever levied at a UK water company for failing to meet consent standards.

Typically RBC's are used for sewage treatment in areas having a population of up to $5000[2,3,4]$. An RBC unit consists of segmented corrugated polymer discs attached together to form a media pack as illustrated in figure 1 ( 4 media packs). The polymer discs, also referred to as media panels, are held within an enclosed basin, submerged by approximately $40 \%$ of the surface area. Wastewater passes through the basin as the disks slowly rotate, at approximately 1 revolution per minute, exposing the biological growth (biomass) on the media discs alternately to the wastewater, and to the surrounding air. 


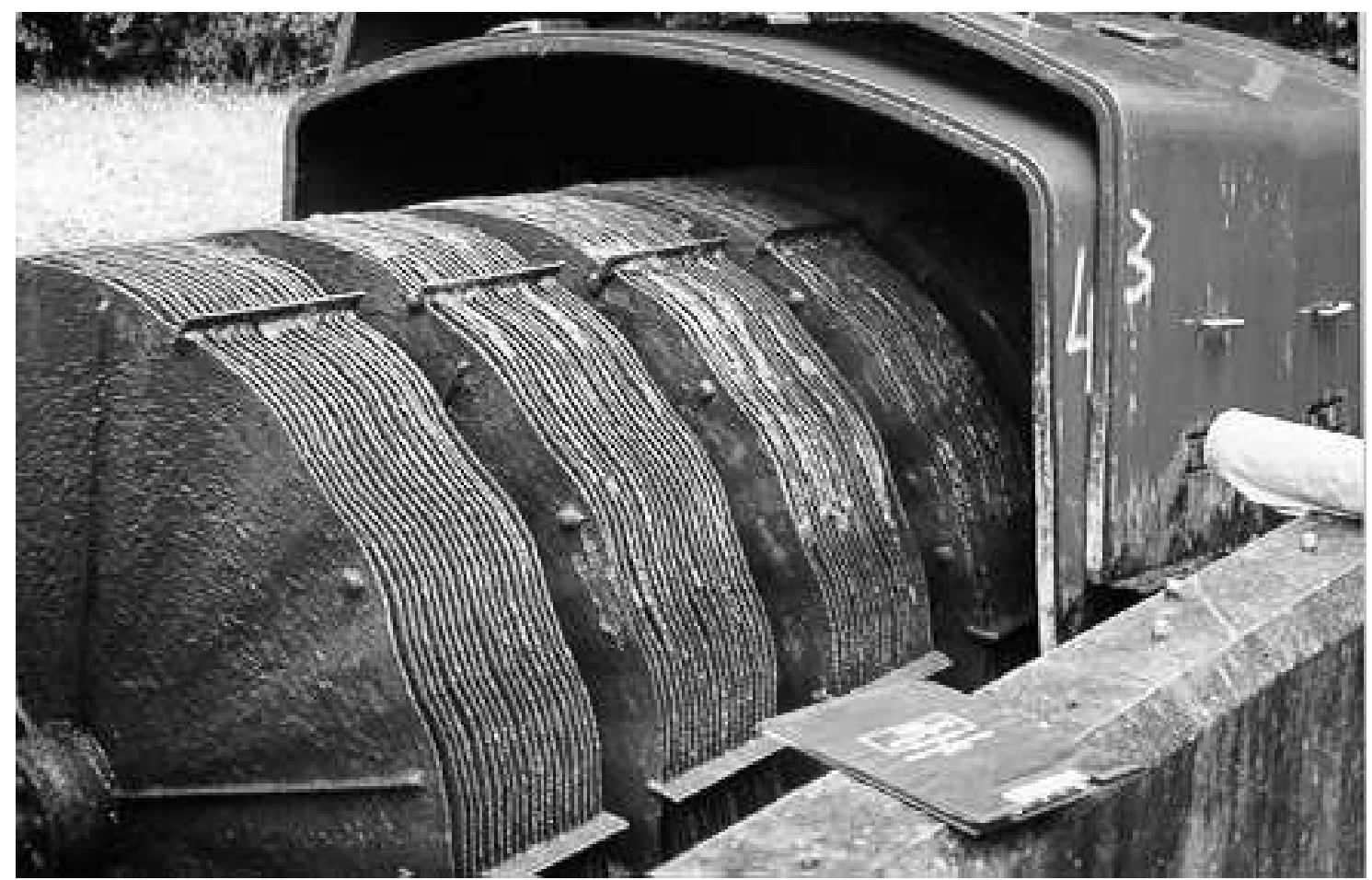

Figure 1 Rotating Biological Contactor

A media pack consisting of a collection of media panels, represents one stage of the treatment process. The biological population that inhabits each stage on an RBC train reflects the environmental and loading conditions specific to each stage; consequently a succession of microfauna develops from stage to stage consistent with the decrease in organic loading with each succeeding stage. The dominant growth in the first stages frequently consists of zoogleal and filamentous bacteria. When the media is exposed to the atmosphere, the liquid film boundary at the air interface immediately becomes saturated with dissolved oxygen (DO). This saturation in turn results in an increase in the mass of oxygen that diffuses into the biofilm. When the media is submerged, oxygen transfer can occur either into or out of the biofilm depending on bulk liquid DO levels and the degree of mixing of the liquid film with the bulk liquid. The overall performance of the biofilm is influenced by both the mass transfer and biological kinetic considerations. 
Whilst it is recognised that the RBC is effective for sewage treatment, several Water Companies in the U.K, USA, Canada, etc. have experienced mechanical failures well before their expiry dates. This has resulted in the discharge of effluent not meeting consent standards forcing operators to adopt alternative treatment methods. In an indepth investigation by the U.S Environmental Protection Agency [5] into the design, operation and maintenance of RBC's, it was concluded that whilst improvements in the design of RBC's can result in more robust units, the loss of mechanical integrity of these units is common and unpredictable. Failures reported by Brenner included shaft breakage, stub shaft damage, media degradation and damage, and bearing failure. Any one, or combination, will result in the loss of operation of the unit.

Mba et. al [6] presented results of a mechanical audit on over $200 \mathrm{RBC}$ 's , the largest survey ever undertaken to date, cataloguing several sudden and catastrophic mechanical failures on RBC's that resulted in loss of operation. Other authors $[7,8,9]$ have also reported mechanical failures in RBC units.

\section{Causes of mechanical failure}

The major factors that have caused mechanical failures on RBC's [6] include:

\section{The effect of the biofilm on the mechanical integrity of RBCs}

The RBC biofilm has two major influences on the mechanical integrity of RBCs; structural loading and microbiologically influenced corrosion (MIC). 


\section{I.i Structural loading}

An understanding of the dynamic loading on $\mathrm{RBC}$ components is vital in determining its mechanical operational life. The loading in this instance is the biomass/biofilm growth on the media panels, water lifted during rotation and drag on the media panels during rotation. Furthermore, observations of biomass thickness over differing seasonal periods have identified bridging of biomass on some units and this results in growths exceeding $5 \mathrm{~mm}$ in depth, see figure 2. Bridging must be avoided, as it results in loss of effective surface area for treatment and increases the loading on the support structure by several multiples. However, estimating anticipated biomass growth is extremely difficult, as it depends on the strength of local sewage (wastewater) being treated.

\section{I.ii Microbiologically influenced corrosion (MIC).}

When sulphide is present, either in the influent wastewater or by its production deep within the biofilm, sulphide oxidising bacteria (SOB) such as Beggiatoa will grow on the biofilm surface. The production of sulphide within the biofilm is due to oxygen depletion. Several authors $[5,10,11,12,13]$ have sighted structural and operational problems on RBC's with heavy biomass growth, due to the presence of Beggiatoa. 


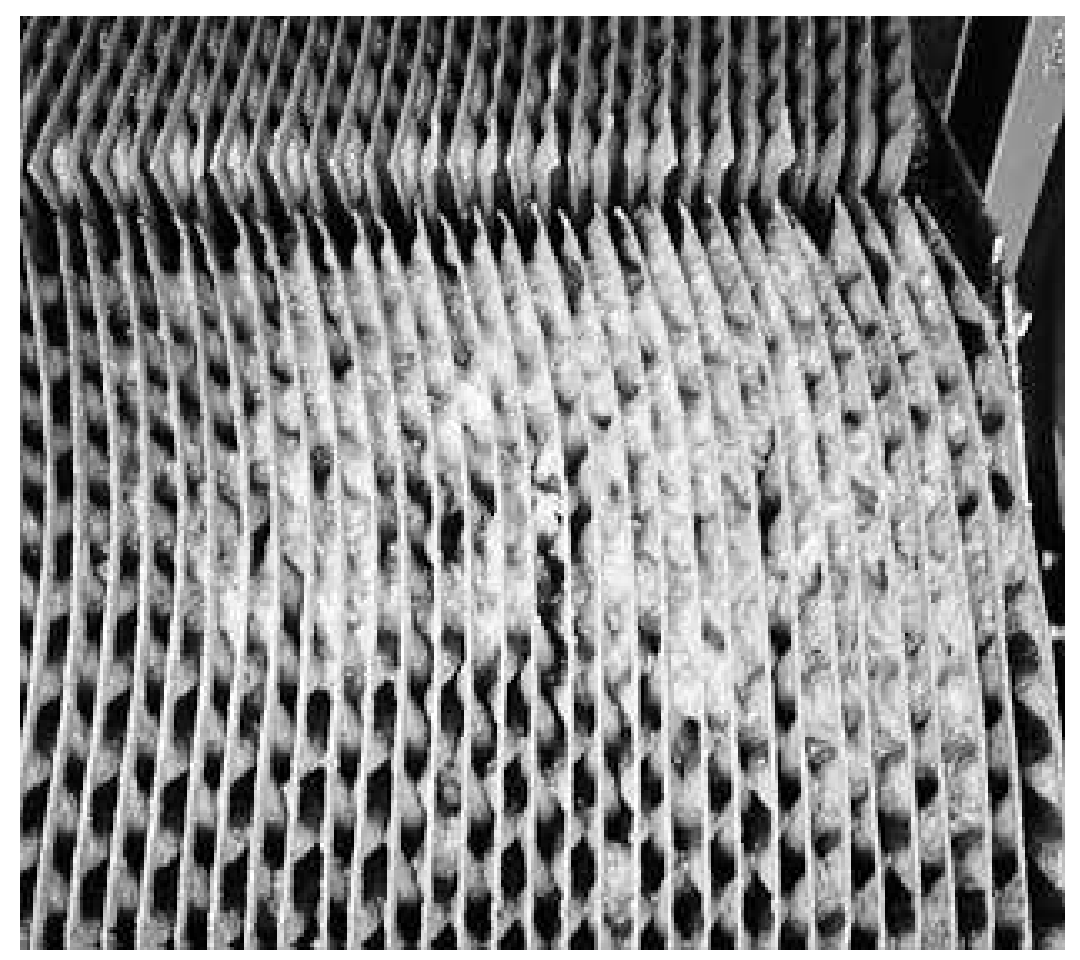

Figure 2 Biomass bridging across a section of the media pack

It is well documented that microbiologically influenced corrosion leads to rapid material deterioration with the most widely acknowledged corrosive organism being the sulphate-reducing bacteria (SRB). Several case studies on stainless and galvanised steels have been reported $[14,15,16,17,18]$ that SRB, SOB and iron reducing bacteria cultures initiated and progressed pitting, and caused intergranular corrosion. Furthermore experimental investigations have [19, 20] have established that sulphides, produced as a by-product of SRB activity, are responsible for enhanced absorption of hydrogen into the steel (HE) resulting in higher corrosion fatigue crack growth rates. 


\section{Fatigue life}

Designing for fatigue calls for an understanding of how the component behaves in a particular stress mode. For example, the stress component could be loaded either in bending, tension/compression, torsion, or a combination of all three. Therefore, when using published data it is always prudent to establish the mode of loading for which the fatigue data was obtained. Moreover, many fatigue tests are conducted on specimens having a good surface finish, usually obtained by grinding or polishing. The better the surface finish the higher the fatigue strength [21]. Codes of practice for corrosion control are usually well documented by water companies. For example, steel components exposed to water should, where possible, be hot-dipped galvanised. Whilst clearly it is important to prevent corrosion, regrettably the practice of galvanising can however have an adverse effect on the fatigue strength of the substrate. The mechanism for failure is attributed a intermediate layer of diffused ironzinc which may crack at stress levels less than the fatigue limit of the steel substrate, thus producing cracks which can penetrate directly into the steel substrate.

Disappointingly there is not a great deal of published data predicting the loss of fatigue strength for zinc coated steel. However, even with such limited data, several researches suggest a $30 \%$ reduction for hit-dipped galvanising and approximately $2 \%$ for zinc electroplating [22, 23, 24, 25, 26, 27]. It has been reported that hot-dipped zinc coating decreases the fatigue limit of high strength steel by approximately $50 \%$, however, this value is reduced for steel of lower tensile strength. Caution should be exercised when using these values, firstly because of the limited data available and secondly these values were obtained for tests in dry air, which is not the environment 
experienced by rotating biological contactors. However Forsman et.al [25] suggests hot-dip galvanising lowers the fatigue limit in air by approximately two-thirds of its value before coating, which remains unchanged when tested in water. This is in contradiction to other published work, but none-the-less useful to know.

It is extremely difficult to predict the corrosive fatigue of metals when continuously exposed to settled sewage, this is because the chemical composition will vary from site to site. Corrosion fatigue strength is defined as the resistance of a metal and its alloys to the formation and development of cracks, which lead to final fracture under the effect of a corrosive environment. At best the designer can only assume the aqueous environment to be fresh water, or at the very worst brackish water. For ordinary unprotected structural steels subjected to fresh water, the reduction in fatigue strength compared to dry air, was found by various researchers to be approximately $70 \%$. However, the results of some early work by Harvey [26], shows that hot-dipped galvanising steel, having $0.47 \%$ carbon in the hardened and tempered condition, a reduction of $28 \%$ was observed. Protection of metal from attack by moisture through the use of hot-dipped zinc galvanising may be advantageous from the point of view of corrosion fatigue, until such time that a fatigue crack appears in the outer zinc coating.

A further reason for concern regarding possible reduction in corrosion fatigue strength is the effect of low frequency applied stress. The lower the cycle frequency of the applied load, the lower the fatigue strength, based upon the same number of loading cycles. Unfortunately again there is little published data available which would assist with the design of sewage treatment plant operating at approximately $0.018 \mathrm{~Hz}$, moreover, fatigue strength depends on the type of corrosive agent. Most of the 
published corrosion fatigue data has been based on tests carried out at loading frequencies of $50 \mathrm{~Hz}$ and over. At much lower loading frequencies, less than $3 \mathrm{~Hz}$, there is a significant drop in the corrosion fatigue life. Several factors are responsible for these phenomena, more significant is the early initiation of cracks [28, 29] and faster crack propagation due to Hydrogen Embrittlement [30 to 39]. The widely held mechanism for this is that, at high loading frequencies, the electrolyte near the tip of the crack is stirred and acidification at the tip is prevented. As a result the rate of hydrogen absorption and anodic dissolution decreases. Since the frequency of cyclic loading is high, the rate of movement of the triaxially stressed region is much greater than that of hydrogen diffusion, therefore, a number of hydrogen atoms will fail to keep pace with the triaxially stressed region. Under these conditions crack growth is governed by mechanical factors only. However, when the frequency of loading is low and the rate of movement of the triaxially stressed region is less than that of hydrogen diffusion, a large number of hydrogen atoms can follow this zone and facilitate the initiation of a mircocrack in the region of triaxial stresses ahead of the crack tip. The growth of the micro crack depends on the time within which hydrogen passes through the zone of triaxial stresses. Other factors that contribute to the lower corrosion fatigue life include anodic dissolution, absorption strength reduction, induced wedge effect, loading waveform and microbiological influenced corrosion.

Gilikman [40] showed the effect of cycle frequency on the corrosion fatigue strength of nickel silicon steel, heat treated by quenching and tempering producing an ultimate tensile strength of $1760 \mathrm{MPa}$. Gilikman's results show the corrosion fatigue strength at $1450 \mathrm{rpm}$ to be $250 \mathrm{MPa}$ which was lowered to $70 \mathrm{MPa}$ at $5 \mathrm{rpm}$. Thereby giving a reduction in fatigue strength of approximately 70\%. Gough [41] also carried out 
corrosive fatigue tests at different frequencies using salt-water and found a reduction of $65 \%$ in fatigue strength at the lower forcing frequencies. Whilst Endo et. al [42] showed a reduction of $58 \%$ by reducing the load cycle frequency from $1000 \mathrm{rpm}$ to 1rpm, their results were found to be dependant on the chemical composition and heat treatment of the steel. The aqueous environment for these latter tests was tap-water. Tests on stainless steel have also been undertaken by Masuda et.al. [43], they found a reduction of $33 \%$ by reducing the load frequency from $3 \mathrm{~Hz}$ to $0.3 \mathrm{~Hz}$ which was increased to $50 \%$ by adjusting the load frequency from $3 \mathrm{~Hz}$ to $0.03 \mathrm{~Hz}$.

The authors take the view that because the corrosive fatigue strength is influenced by the chemical composition of the steel, in addition to probable heat treatment and the likelihood that the steel has experienced previous cold working, then a guarded design strategy would be to consider the cumulative effect of both hot-dip galvanising and the influence of low frequency loading, accordingly the following is suggested. Given that most steels the endurance fatigue limit is $50 \%$ of the ultimate tensile strength, also considering that hot-dip galvanising reduces this value by approximately a further $30 \%$ and low frequency loading an extra $50 \%$, then the combined effect is $17.5 \%$ of the ultimate tensile strength for rotating bending. For example, for a structural steel having an ultimate tensile strength of $450 \mathrm{MPa}$ the corrosive fatigue strength would be 78.75 MPa. This value would need to be reduced even further if welded structures are employed. 


\section{The shaft-less RBC}

There have been many reported instances, where the main supporting shaft of a RBC has fractured across its diameter, resulting in complete collapse of the unit. Indeed shaft failure is by no means restricted to the larger $\mathrm{RBC}$, but is associated with the cyclic stress levels operating within the shaft and the corrosion fatigue strength of the shaft material. However, it is the 'larger RBC' where cost savings are significant. Conventional shaft design of an $\mathrm{RBC}$, dictates that the bending stress caused by the biomass loading, is the major influencing factor when selecting the size of the hollow shaft. In contrast, when designing a shaft-less RBC where successive media panel are clamped together using interconnecting beams, major stresses are caused by the shear force loading, as opposed to bending couples. Disappointingly, when studying the effects of shear loading in steel frames, the method of finite element analysis is usually considered to be the most appropriate method of analysis. Such techniques are more often than not unavailable to the smaller company. This paper address the problem of frame stresses, by considering the application of 'guided' beam theory, whereby, the media pack frames and the frame between packs are analysed using both bending and shear loading. As part of a feasibility study, the results for a typical 4.0 metre RBC is studied using guided beam theory and compared using finite element analysis; see appendix A.

\section{Stress in a symmetrical elastic shaft subject to pure bending.}


The bending neutral axis for rotating shafts lies along the axis of rotation; moreover, the axis of rotation must coincide with the centroid of the shaft if an unbalanced rotor is to be avoided. Mathematical expressions for calculating the second moment of area, sometimes referred to as bending inertia, for a hollow circular shaft are well established [44]. However, if the shaft no longer consists of a continuous hollow structure, but is made up of a number of individual components equally positioned both circumferentially and radially from the axis of rotation, then the second moment of area about a non-centroidal axis may be expressed in terms of the moment of inertia about a parallel centroidal axis, known as the parallel axis theorem, which may be described by the following equation:

$$
\mathrm{I}_{\mathrm{Xx}}=\mathrm{I}_{\mathrm{X}^{\prime} \mathrm{X}^{\prime}}+\mathrm{AR}^{2}
$$

It must be emphasised that when applying the above stress calculation procedures to bending of beams, it is assumed that the affect of shear is negligible, which is not the case when dealing with structures associated with rotating biological contactors due to elastic distortions [45].

The shaftless RBC unit consists of two end frames of the media pack connected to each other by a number of inter connecting beams. These interconnecting beams must be capable of transmitting the combined bending and shear stress from media pack to adjacent packs, without the use of a hollow through shaft. Therefore, designs studies which only make use of the bending equation when calculating the bending stress in the interconnecting beams, automatically neglect the influence of shear. Such 
calculations will inevitably result in underestimating the working stress level and may even lead to failure of the structure.

2. Stress in a symmetrical elastic frame structure subject to combined bending and shear.

In order to examine more closely the influence of shear loading on the interconnecting beams, it is helpful to consider the elastic behaviour of these longitudinal beams between end frames, as illustrated in figure 2. Here it is assumed that the biomass loading is reacted by the end frame of individual media packs, as indicated by the variable ' $\mathrm{F}$ '

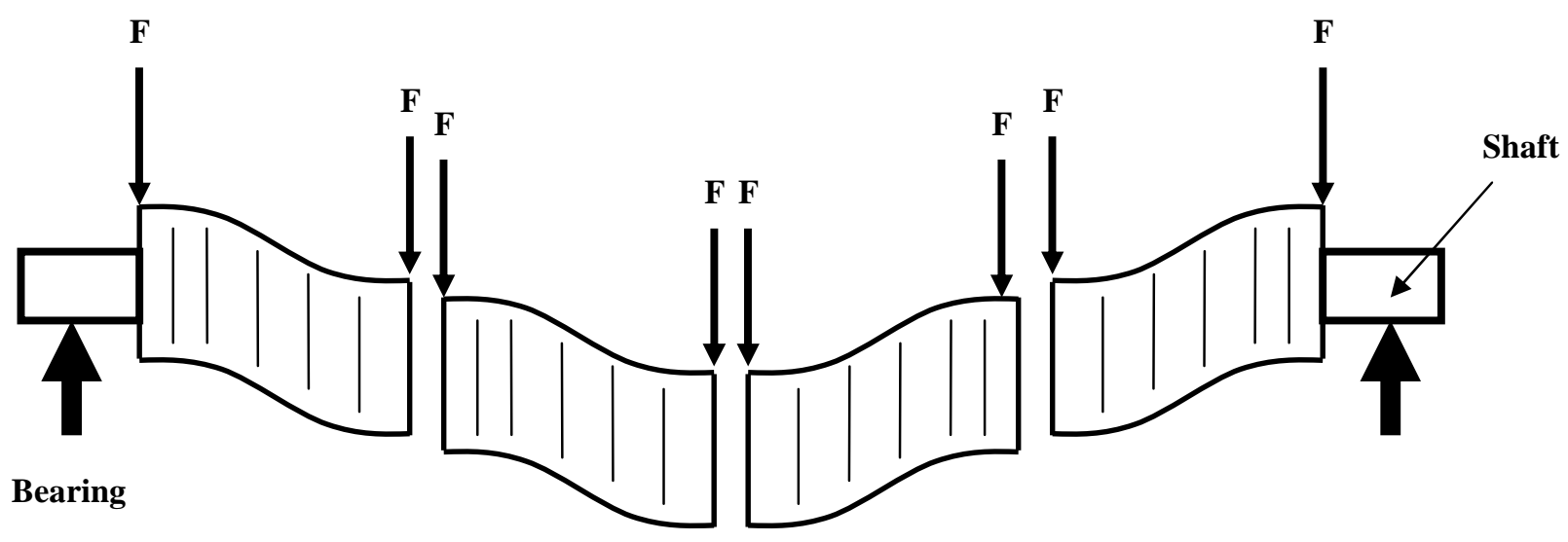

Figure 2 Schematic diagram illustrating local distortion of interconnecting beams; F - Biomass loading

The loading from each media pack is shared equally by the interconnecting beams. Moreover, it is assumed that the longitudinal beams do not physically support the media segments, thereby allowing long-established design configurations for supporting the media segments using conventional through rods to be exploited. A 
decision made on commercial grounds, as it allows existing moulds to be used when manufacturing the polymer media panels.

Consider a single media pack where the two end frames are connected to each other by a number of interconnecting longitudinal beams. From observation of figure 2, it can be seen that the slope is zero at the distal ends of the beam. However, whilst the slope at the ends is zero, the deflection does have a specific value. To study this affect further, consider a single beam built-in at the one end, whilst the opposite end is free to deflect but constrained from rotation. Employing the slope/deflection method the resulting bending moment along the length of the beam is given by:-

$$
\mathrm{BMt}=\mathrm{FL} /(2 \mathrm{~N})
$$

where ' $F$ ' is the total reactive load of the media pack acting on the end frame.

' $\mathrm{L}$ ' is the length of the media pack.

' $\mathrm{N}$ ' is the total number of interconnecting beams.

It perhaps interesting to note that using traditional bending stress procedures, the resulting maximum value occurs midway between the bearings. However, using equation (2) the maximum stress occurs at the end pack closest to the bearing. A comparative application study is detailed in appendix A.

\section{Discussion and Conclusion}

In analysing the mechanical integrity of an $\mathrm{RBC}$ or in creating a new design, it is necessary to consider the cumulative effect of low frequency corrosion fatigue and microbiologically influenced corrosion. The fatigue strength of metals is reduced in a 
corrosive environment and reduced even further at low frequencies of loading. These factors have the effect of removing any fatigue design limits, consequently, under these circumstances every structural component will eventually fail. Furthermore, galvanised and zinc-plated steels are also susceptible to low frequency corrosion fatigue. These mechanisms have resulted in mechanical failures of RBCs which, in some instances, has resulted in operators failing to meet consent standards and hurriedly installing temporary treatment plants whilst the RBC is out of operation.

Although all the necessary information on low frequency corrosion fatigue or the influence of MIC on structural steels members at low speeds of loading is not available in the public domain, primarily because the research has not been undertaken, the design engineer is encouraged by the authors to observe trends in low frequency corrosion fatigue data available. These trends will direct the engineer to the appropriate stress levels that can ensure an operational life of twenty years. Whilst there is no proof to date on the effect of MIC on the structural members of RBC's, it is highly probable that the fatigue strength of structural members is reduced by this phenomenon. This is based on the evidence presented and the case studies reported, particularly on the influence of hydrogen at low frequencies of loading.

The analytical technique proposed for modelling framed structures, for use on shaftless RBC's has been shown to be reliable, giving results slightly higher than the more accurate finite element method, see appendix A. The simple feasibility model studied, comprising of 12 continuous longitudinal box section beams $150 \mathrm{~mm} \times 150 \mathrm{~mm}$ with $8 \mathrm{~mm}$ thickness, used to replace the hollow tubular shaft 610 diameter having $50 \mathrm{~mm}$ wall, shows the framed structure to have a mass half that of the hollow shaft, thereby, 
demonstrating a significant cost reduction. Furthermore, suppliers of rectangular steel box section should be more readily available, than suppliers of large hot rolled hollow tubing. Moreover, use of tubes structures should provide a greater opportunity for modular design facilitating ease of media pack replacement.

The mechanical design of an $\mathrm{RBC}$ is not simply selecting the best material to perform a particular function based on stress levels, but is more concerned with the corrosion (chemical and biological) and fatigue behaviour of the various materials chosen at low speeds of loading. Failure to understand these requirements is probably why so many failures have been experienced after the unit has been in operation only a few months or years of service. With a thorough understanding of the mechanisms of mechanical failure, a new approach to RBC design will reduce the occurrence of mechanical failure and ensure that effluent consent standards are maintained continuously.

\section{References}

1. The Daily telegraph, UK, Tuesday March 19, 2002

2. ASCE Manual on Engineering practice, (1977) Waste Water Treatment Plant design, 36, 309-312.

3. Tchobanoglous, G. and Burton, F.L. (1990) Wastewater Engineering Treatment, Disposal and Reuse, publisher Metcalf \& Eddy Inc., 3rd edition. Copyright McGraw-Hill, USA. ISBN 0-07-041690-7.

4. Findlay, G. E., (1993) The selection and design of rotating biological contactors and reed beds for small sewage treatment plants, Proc. Institution of Civil Eng. Water and Energy, 101, 237-246, Water Board paper 10249. 
5. Brenner, R.C. and Opaken, E.J. (1984) Design information on Rotating Biological Contactors Design, Technical report no. EPA-600/2-84-106, Municipal environmental research laboratory, Cincinnati, Ohio, USA.

6. D. Mba, R. H. Bannister, Mr. G. E. Findlay, Mechanical redesign of the Rotating Biological Contactor. Water Research, Journal of the International Association on Water Quality, Water Research, Vol. 33, N0. 18, pp 3679$3688,1999$.

7. Horan, N.J. (1991) Biological Wasterwater Treatment Systems, Theory and Operation, Pub. John Wiley and Sons, Chichester, UK

8. Nibbering, J. J. W. (1982) Behaviour of mild steels under very low frequency in seawater. Corrosion Science, 23(6), 645.

9. Tchobanoglous, G. and Burton, F.L. (1990) Wastewater Engineering Treatment, Disposal and Reuse, publisher Metcalf \& Eddy Inc., 3rd edition. Copyright McGraw-Hill, USA. ISBN 0-07-041690-7.

10. Surampalli, R.Y.,Tekippe,R.J. and Baumann, E. R. (1994) Value of Supplemental Air in improving RBC performance, Water Poll. Res. J., 29(1), 53-73.

11. Surampalli, R.Y., and Baumann, E. R. (1992) RBC Kinetics in Treating Domestic and Industrial Dairy Wastewater under low and high organic loading conditions. Water Poll. Res. J, 27(4), 665-691.

12. Hitdlebaugh, J.A., Miller, R. D. (1980) Full-scale biological rotating contactor for secondary treatment and nitrification. Proceedings of the first National Symposium on RBC technology, Champion, PA, 269. 
13. Chesner, W.H. and Iannone, J.J. (1968) Review of current RBC performance and design procedures. Report prepared for U.S. EPA under contract No. 6802-2775.

14. Ringas,C. and Robinson, F.P.A. (1988) Corrosion of Stainless Steel by Sulfate-Reducing Bacteria- Total Immersion Test Results. The Journal of Science and Engineering Corrosion, 44(9), 671-678.

15. Ringas,C. and Robinson, F.P.A., (1987) Corrosion of Stainless Steel by Sulfate-Reducing Bacteria-Electroochemical Techniques. The Journal of Science and Engineering Corrosion, 44, No. (6), 386-396.

16. Wagner, P.A. and Ray, R.I. (1994) "Surface analytical techniques for microbiologically influenced corrosion-A review", Microbiologically Influenced Corrosion Testing, American Society for Testing and Materials, Special technical publication (ASTM STP 1232), Philadelphia, 153-169.

17. Borenstein, S.W, (1991) "Why does Microbiologically Influenced Corrosion occur preferentially at welds?", Proceedings, Corrosion / 91, Paper 286, National Association of Corrosion Engineers (NACE), Houston, Texas, USA.

18. Tatnal, R. E.(1981) Case histories: Bacteria-influenced corrosion. Proceedings Corrosion/81, paper 130, National Association of Corrosion Engineers, Houston, Texas, USA.

19. Hoyt, S. L. (1943) Metals and alloys data book. Copyright Reinhold publishing corporation, New York, USA.

20. Kilgallon, P.J., The effect of sulphate Reducing bacteria on the hydrogen absorption of cathodically protected high strength low alloy steels, $\mathrm{PhD}$ Thesis 1993-94, Cranfield University.

21. Engineering Sciences Data Unit ESDU No. 74027 
22. Prediction of fatigue resistance of a hot-dip galvanised steel. J.B. Vogt et.al., Blackwell Science Ltd., Fatigue Fract. Engng. Mater. Struct. 2001

23. Nilsson, T., et. al., Fatigue properties of hot-dip galvanised steel. Scandinavian Journal of Metallurgy 18, 1989.

24. Corrosion of steel in various aqueous environments. A. Ragab et. al., Fatigue Fract. Engng. Mater. Struct. Vol 12 No 6.

25. Forsman, O. and Lundin, E. (1951) The influence of different surface coatings on the fatigue strength of steel. Proceedings of the 1st world Metallugists congress of American Society of Metallugists, 606-612.

26. Protective coating against corrosion fatigue of steel. W. E. Harvey, Metals and Alloys, Vol. 11930 and Vol. 21932.

27. Automatic narrow groove welding process for heavy walled pipe piles of offshore structures. Toyouki Bado et. Al. Nippon Steel Technical Report, Overseas No9, April 1977

28. Komai, K., Minoshima, K., and Kinoshita, S. (1988) Corrosion fatigue crack initiation behaviour of high tensile strength steels in synthetic seawater, Japan Society of Mechanical Engineers (JSME) International journal, 31(3), 602612.

29. Komai, K. (1987) Corrosion fatigue crack growth retardation and enhancement in structural steels, Current Japanese materials research, 1, 267-289.

30. Nibbering, J. J. W. (1982) Behaviour of mild steels under very low frequency in seawater. Corrosion Science, 23(6), 645.

31. Minoshima, K, and Komai, K., (1988) Stress corrosion cracking of highstrength steels under dynamic loading conditions. Current Japanese materials research, 4, 123-147. 
32. Vosikovsky, O. (1975) Fatigue crack growth in an X-65 line pipe steel at low frequencies in an aqueous environment. Engineering materials and technology, 10, 298-304.

33. Boyer, E.H., (1984) Editor, Metals Handbook, 13, Corrosion fatigue failures the effects of frequency. American Society for Metals.

34. Corrosion fatigue: chemistry, mechanics and mircostructure. National Association of Corrosion Engineers (NACE) - 2, (1971), Conference held at University of Connecticut, Storrs, Connecticut, USA.

35. Oriani, R.A. (1987) Hydrogen - The versatile embrittler, Corrosion, 43(7), 390 $-453$.

36. Parkins, R. N., (1980) Aqueous environmental influences in corrosion fatigue. Proceedings of the first USSR-UK seminar on corrosion fatigue of metals, Corrosion Fatigue, edited by Parkins, R.N, and Kolotyukin, Ya. M., held at Lvov, USSR. Published by the Metals Society, London, 36-46, ISBN 0904357-51-1.

37. Speidel, M. O. (1977) Corrosion fatigue in Fe-Ni-Cr alloys. In Stress corrosion cracking and hydrogen embrittlement of iron base alloys. National Association of Corrosion Engineers (NACE), 5, Houston, Texas, USA, 1071-1094.

38. Gabetta , G., Rinaldi, C., Pozzi, D., (1990) A model for environmentally assisted crack growth rates. In conference on Environmentally Assisted Cracking: Science and Engineering, Proceedings of the American Society for Testing Materials (ASTM), STP 1049, Pennsylvania, USA. 266-282.

39. McEvily, A. J. Jr. (1990) Atlas of stress corrosion fatigue curves. Copyright ASM International, Ohio 44037, USA. ISBN 0-87170-374-2. 
40. L.A. Glikman, Corrosion - Mechanical strength of metals. (Russian translation).

41. Gough, H. J., The corrosion fatigue of metals. J. Inst. Met. Vol 49 Pt 111932.

42. K. Endo and Y Miyao. Effect of cycle frequency on the corrosion fatigue strength. Bulletin of JSME Vol. 1 No.4 1958.

43. Masuda et. al Corrosion fatigue life prediction for SUS 403 stainless steel in $3 \% \mathrm{NaCl}$ aqueous solution. Trans. of Japanese Society of Mechanical Engineers. 58 480, pp 1740 to 1769.

44. Formulas for Stress and Strain Raymond J. Roark, Warren C. Young (Editor), Richard G. Budynas (Editor), McGraw-Hill Education, ISBN: $007072542 X$.

45. R. garcia de Oteyza Gonzalez-Hontoria, Design of a shaft-less rotating biological contactor, MSc thesis, School of Engineering, Cranfield University, 2004.

\section{APPENDIX A: Practical application of the 'guided' beam theory}

In order to demonstrate the application of equation (2) the following typical large RBC was analysed, moreover, the results were verified using finite element analysis. 
Diameter of media pack - - . - . - - 4. $4.0 \mathrm{~m}$

Length of media pack - . - . - . - - $1.5 \mathrm{~m}$

Number of packs - . . . . . . . . . 4

Number of discs per pack - - - - - - - 78 .

Depth of media corrugations - - - - - - 0.019m

Number of media pack segments - - - - 8

Number of media pack through rods - - - 24 total

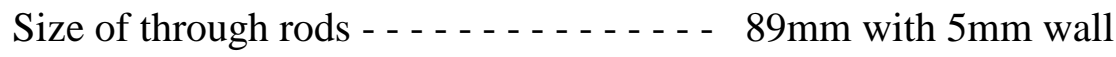

Polymer media thickness - - - - - - - - $0.9 \mathrm{~mm}$

Biomass thickness - . . . . . . . . $3 \mathrm{~mm}$ on all 4 pack

Length of shaft between bearings - - - - $9.5 \mathrm{~m}$

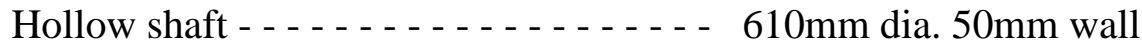

Depth of immersion - - . - . - - - $1.6 m$

Drive motor - - - - - - - - $1.5 \mathrm{~kW}$ at $1 \mathrm{rpm}$.

Figure 3 illustrates the shaft-less construction of the RBC used for both the analytical and finite element studies. The interconnecting longitudinal beams used to support the media panels was chosen to be a box section $150 \mathrm{~mm} \times 150 \mathrm{~mm}$ with $8 \mathrm{~mm}$ wall by $1500 \mathrm{~mm}$ long, the total number of box sections for each media pack was 12 . 


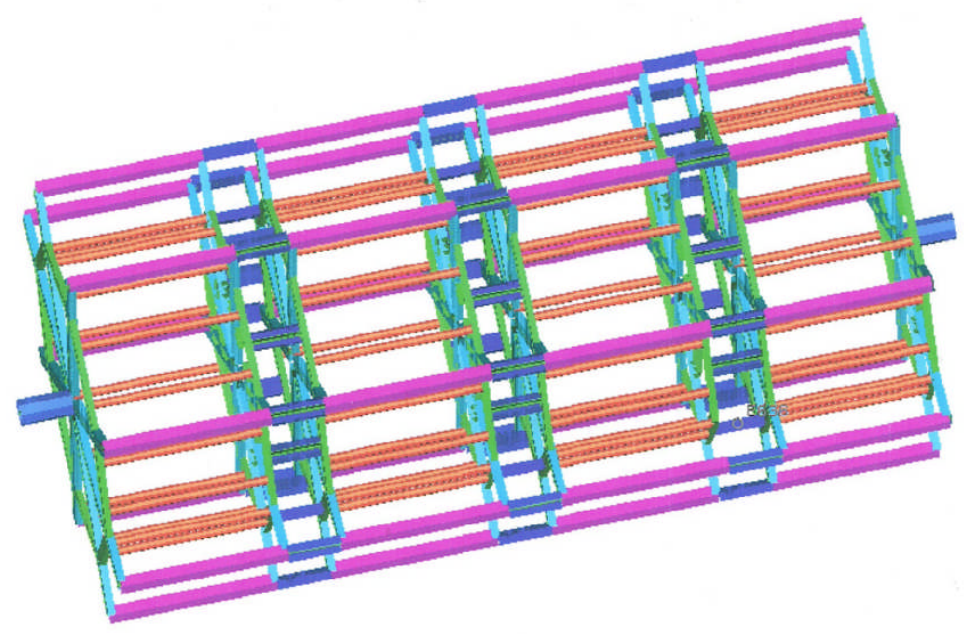

Figure 3 View of RBC frame illustrating interconnecting beams for four media pack [45]

The mass of the polymer media panels, plus biomass; draining off water, and mass of frame was evaluated and found to be in the order of $8,400 \mathrm{~kg}$ per media pack. This value takes into account the $40 \%$ immersion of the rotor into the sewage liquor. Using this value it is now possible to determine the shear force acting along the length of the RBC between bearings, as demonstrated in figure 4 . 


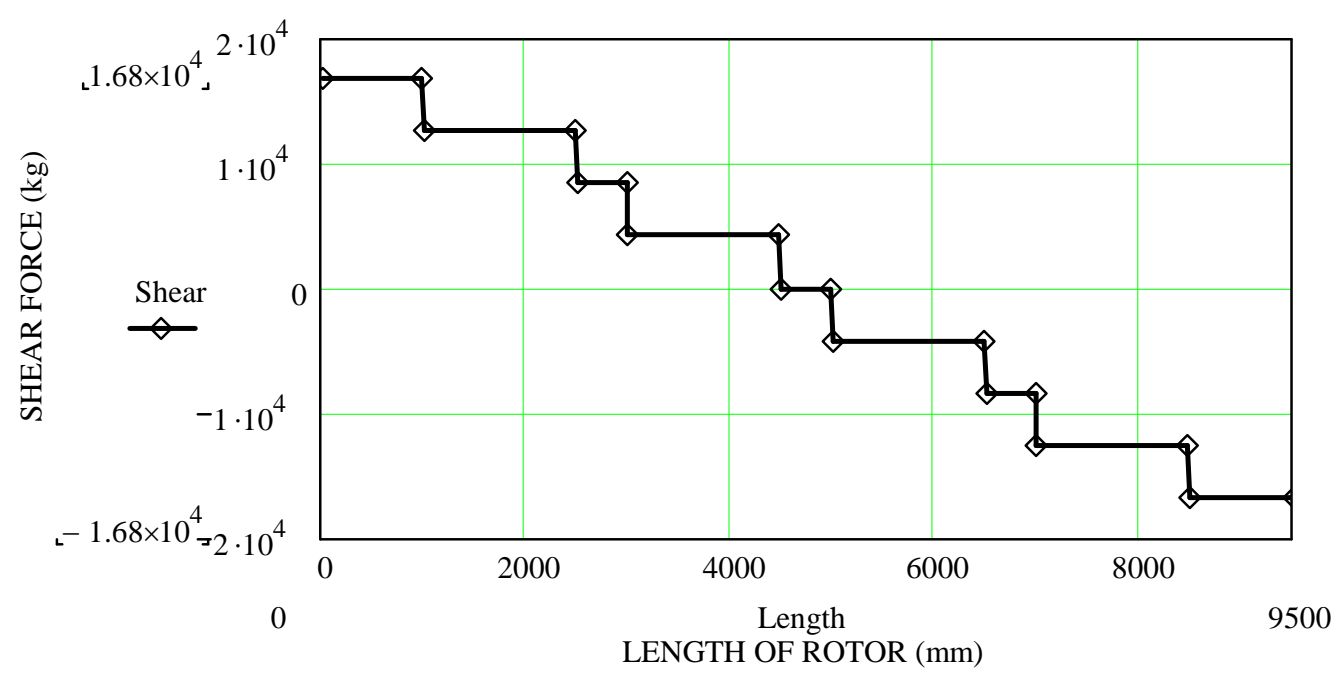

Figure 4 Shear force diagram for shaft-less rotor $(\max$. shear $=16800 \mathrm{~kg})$

Figure 4 shows the maximum shear force occurs in the media end frame close to the bearings, for the example studied, the maximum shear is equivalent to $16,800 \mathrm{~kg}$. Using equation (2) and noting that the second moment of area for the $150 \times 150$ box section is $15.1 \times 10^{-6} \mathrm{~m}^{4}$ the bending moment and the associated bending stress, is obtained as follows:-

$$
\begin{aligned}
& \text { BMt. }=\frac{16800 \times 9.807 \times 1.5}{2 \times 8}=1.545 \times 10^{4} \mathrm{Nm} \\
& \sigma_{\text {bending }}=\frac{1.545 \times 10^{4} 0.075}{15.1 \times 10^{-6}}=76.74 \mathrm{MPa} .
\end{aligned}
$$

In addition to the bending stress in each of the box sections, it is necessary to consider the shear stress in each of the rectangular beams due to gravitational loading thus:- 
Maximum shear loading of media packs and biomass $=16,800 \mathrm{~kg}$.

$$
\text { Area of box section }=4.51 \times 10^{-3} \mathrm{~m}^{2}
$$

Average shear stress in box section due to mass of media pack and biomass:-

$$
\sigma_{\text {shear }}=\frac{16800 \times 9.807}{12 \times 4.51 \times 10^{-3}}=3.04 \mathrm{MPa}
$$

In addition to the shear stress caused by gravitational loading, it would be prudent to consider the shear stress caused by the transmitted torque-

Shear stress in rectangular hollow beam caused by electric motor:-

$$
\begin{aligned}
& \text { Using the formula } \mathrm{kW}=\frac{\mathrm{TN}}{9550} \\
& \text { were } \mathrm{T} \text { is torque }(\mathrm{N} . \mathrm{m}) \\
& \mathrm{N} \text { is speed }(\mathrm{rpm}) \\
& \mathrm{T}=\frac{9550 \times 1.5}{1}=1.433 \times 10^{4} \mathrm{Nm}
\end{aligned}
$$

Shear stress in beam:-

$$
\sigma_{\text {torsion }}=\frac{1.433 \times 10^{4}}{12 \times 2.0 \times 4.51 \times 10^{-3}}=0.132 \mathrm{MPa}
$$

This latter shear stress suggests that the frame is rigid from a torsional point of view, moreover, this value of stress is so small that it can be neglected when calculating the factor of safety. Using the above stress values, the maximum Von Mises stress was calculated and found to be $\pm 76.92 \mathrm{MPa}$. i.e. for complete reversal bending and shear stresses.

In order to complete the feasibility study, it would be logical to consider the bending moment distribution along the length of the rotor. Therefore, using the shear force results described above, the resulting bending moment distribution is shown in figure 
5, where it should be noted that the maximum bending moment is given as 453,100 kg.m. It is important to note that the maximum value for the bending moment occurs where the shear force is zero. For this condition the bending stress may be computed using the transformation of axis theory, as described by equation (1).

For the type of structure under consideration $I_{X^{\prime} X^{\prime}}$ nay be neglected, furthermore, the neutral axis is taken to be the same as the axis of rotation. Therefore, the second moment of area for the interconnecting beams is given by:-

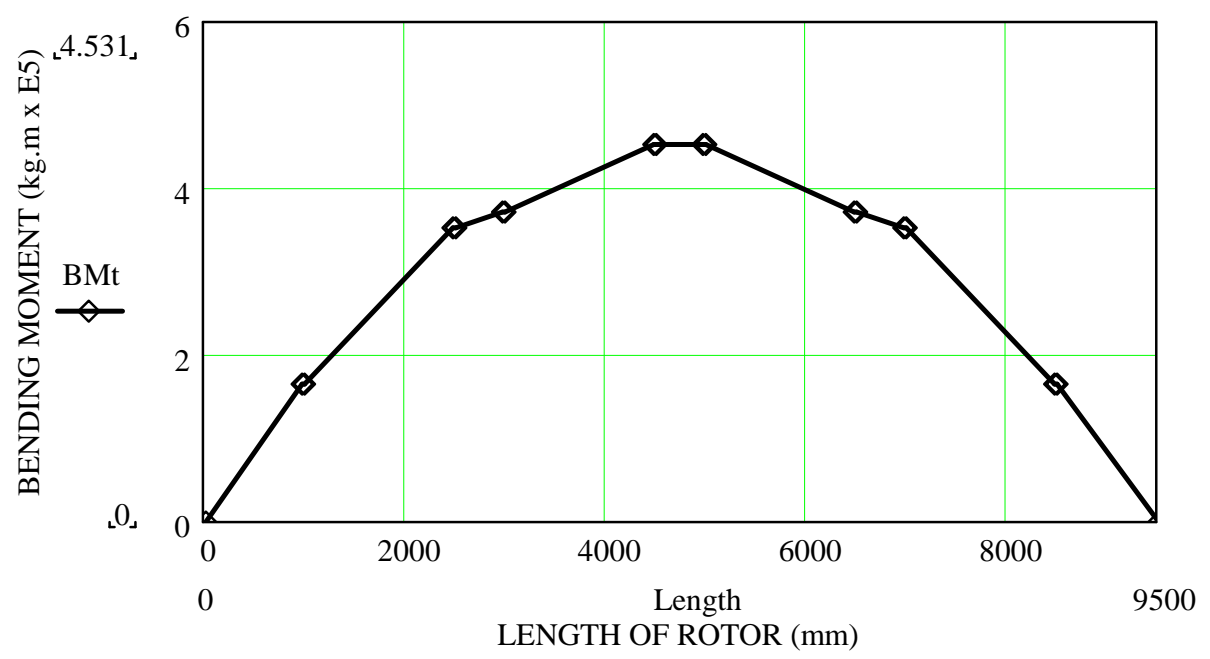

Figure 5 Bending moment distribution along length of rotor

$$
\mathrm{I}_{\mathrm{Xx}}=\mathrm{AR}^{2}=0.125 \mathrm{AD}^{2} \mathrm{~N}
$$

where $\mathrm{A}$ is the cross-sectional area of the interconnecting beam.

$\mathrm{D}$ is the equivalent pitch circle diameter of the interconnecting beams.

$\mathrm{N}$ is the number of interconnecting beams. 
Hence the bending stress in the interconnecting beams, at the centre of the rotor, is calculated as follows:-

$$
\begin{gathered}
\mathrm{I}_{\mathrm{XX}}=\mathrm{AR}^{2}=0.125 \mathrm{AD}^{2} \mathrm{~N}=0.125 \times 45.1 \times 10^{-4} \times 4^{2} \times 8 \\
\therefore \mathrm{I}_{\mathrm{XX}}=0.072 \mathrm{~m}^{4} \\
\sigma_{\text {bending }}=\frac{4.531 \times 10^{5} \times 2}{0.072}=12.58 \mathrm{MPa} .
\end{gathered}
$$

From the above analysis it has to be concluded that the maximum bending stress in the interconnecting beams, occurs in the media packs at the end of the rotor. Therefore, in order to vindicate the theoretical analysis, the same frame structure was also analysed using finite elements. The results from this analysis identified the maximum Von Mises stress point to be also located in the media packs, in the vicinity close to the bearings, having a value of $\pm 70.4 \mathrm{MPa}$ compared to $\pm 76.92 \mathrm{MPa}$ using the hand tabulation technique. The reason for the slightly lower value was attributed to local distortion of the media end frame, thereby introducing a small slope at the ends of the interconnecting beams. In other words, the beam was not exactly a guided cantilever. 